Tropical Journal of Pharmaceutical Research November 2014; 13 (11): 1783-1789

ISSN: $1596-5996$ (print); 1596-9827 (electronic)

(C) Pharmacotherapy Group, Faculty of Pharmacy, University of Benin, Benin City, 300001 Nigeria.

All rights reserved.

Available online at http://www.tjpr.org

Original Research Article

http://dx.doi.org/10.4314/tjpr.v13i11.2

\title{
Effect of Methyl Jasmonate and Silver Nanoparticles on Production of Secondary Metabolites by Calendula officinalis L (Asteraceae)
}

\author{
Faezeh Ghanati* and Somyeh Bakhtiarian \\ Department of Plant Biology, Faculty of Biological Science, Tarbiat Modares University, Tehran, Iran \\ *For correspondence: Email: ghangia@modares.ac.ir; Tel: 00982182884403, 009100025315 \\ Received: 9 September 2013 \\ Revised accepted: 4 September 2014
}

\begin{abstract}
Purpose: To investigate the effects of two elicitors, methyl jasmonat (MeJA) and silver nanoparticles (SNPs), on the production of secondary metabolite by Calendula officinalis $L$ (marigold).

Methods: For the extract of the aerial part of the plant, membrane lipid peroxidation rate and 2, 2 'diphenylpicrylhydrazyl (DPPH) radical scavenging activity were assessed along with total anthocyanin, flavonoid, chlorophyll, carotenoids and saponin content. The effect of $C$. officinalis $L$ extract with and without SNPs and MeJA on HeLa cell viability was also evaluated by methylthiazol tetrazolium (MTT) assay.

Results: The presence of SNPs and MeJA in marigold extract increased membrane lipid peroxidation but decreased DPPH radical scavenging activity. Anthocyanin and flavonoid content also decreased in all the treatments investigated. Exposure to SNPs decreased chlorophyll and carotenoid content in the plant by 30 - 50\%, while MeJA increased them. In comparison with the control group, treatment with 0.4 mM SNPs and $100 \mu \mathrm{M}$ MeJA increased saponin content in the plants by up to $177 \%$. Exposure of HeLa cells to the extracts of marigold significantly reduced their viability and this reduction was more pronounced when the plants were treated with MeJA and SNPs.

Conclusion: Treatment of C. officinalis L. with SNPs and MeJA seems to be a simple and cost-effective method of improving the medicinal properties of this plant.
\end{abstract}

Keywords: Calendula officinalis, Silver nanoparticles, Methyl jasmonate, Secondary metabolites, HeLa cells, Membrane lipid peroxidation, Radical scavenging

Tropical Journal of Pharmaceutical Research is indexed by Science Citation Index (SciSearch), Scopus, International Pharmaceutical Abstract, Chemical Abstracts, Embase, Index Copernicus, EBSCO, African Index Medicus, JournalSeek, Journal Citation Reports/Science Edition, Directory of Open Access Journals (DOAJ), African Journal Online, Bioline International, Open-J-Gate and Pharmacy Abstracts

\section{INTRODUCTION}

Calendula officinalis L (Asteraceae), commonly known as marigold, is an annual herbaceous plant native to Mediterranean countries. Marigold petals are widely used in traditional and homeopathic medicine as infusions and ointments to treat inflammation, tumor, wound healing, as well as protect from free radicals [1]. Moreover, marigold extract has been linked to the inhibition of HIV-1 virus replication following infection [2]. Much of the therapeutic activity of this plant is attributed to its flavonoids, volatile oil, carotenoids, terpenoids, coumarins, and alkaloid [1].

Besides other natural products, the flowers of $C$. officinalis contain saponins. These compounds have a diverse range of properties, including sweetness and bitterness, foaming, emulsification, pharmacological and medicinal properties, hemolytic properties, as well as anti- 
microbial, insecticidal, and molluscicidal activities [3]. One efficient way to increase the production of these products in the plant is treatment with chemical elicitors such as methyl jasmonate (MeJA). Jasmonates are endogenous phytohormones of the plants. They are potent elicitors or signaling agents that influence a great diversity of physiological and biochemical processes. Several studies have shown that jasmonates trigger the accumulation of secondary metabolites, such as alkaloids and anthocyanins, in plants [4]. Increase of paclitaxel in Taxus, rosmarinic acid in Culeus blumei, anthocyanins in strawberry and grapevine have been reported after adding jasmonate to their suspension cultures $[5,6]$.

Silver nanoparticles (SNPs) have long been known to exhibit strong anti-microbial activity [7]. Secondary metabolites present in plant systems may be responsible for the reduction of silver and synthesis of nanoparticles [7]. However, to the best of our knowledge, the effect of SNPs on secondary metabolites in plants has not been published. In this study, we investigated the effects of SNPs and MeJA on secondary metabolites of $C$. officinalis. In particular, we assessed the rate of membrane lipid peroxidation, 2.2'diphenylpicrylhydrazyl (DPPH) radical scavenging activity, and survival of HeLa cells.

\section{EXPERIMENTAL}

\section{Plant materials and treatments}

Calendula officinalis $L$ in its vegetative growth stage was purchased from a garden in Tehran, Iran in September 2012. It was identified and authenticated by Dr Vali-allah Mozaffarian of the Institute of Forests and Rangelands Research, Tehran, Iran and a voucher specimen deposited at the herbarium of the institute. The plants were allowed to continue growing in a modified Hoagland nutrient solution with a 16/8 h photoperiod. The nutrient solution contained 0.46 $\mathrm{mM} \mathrm{K}_{2} \mathrm{SO}_{4}, 0.1 \mathrm{mM} \mathrm{KH}_{2} \mathrm{PO}_{4}, 0.73 \mathrm{mM} \mathrm{NH}_{4} \mathrm{NO}_{3}$, $0.713 \mathrm{mM}\left(\mathrm{NH}_{4}\right)_{2} \mathrm{SO}_{4}, 0.046 \mathrm{mM} \mathrm{H}_{3} \mathrm{BO}_{3}, 0.002$ $\mathrm{mM} \mathrm{CuSO}_{4}, \quad 0.032 \mathrm{mM}$ Fe-EDTA, $0.41 \mathrm{mM}$ $\mathrm{MgSO}_{4}, 0.5 \mathrm{mM} \mathrm{CaCl}, 0.0091 \mathrm{mM} \mathrm{ZnSO}$, $0.0026 \mathrm{mM} \mathrm{Na}_{2} \mathrm{MoO}_{4}$, and $0.09 \mathrm{mM} \mathrm{MnSO}_{4}$, with the $\mathrm{pH}$ adjusted to 5.8 and the nutrient solution exchanged every 4 days. During the flowering stage of growth, the plant was treated for $24 \mathrm{~h}$ with 0,50 , and $100 \mu \mathrm{M}$ of MeJA (Sigma-Aldrich, St. Louis, MO, USA), and $0.4,0.8,1.2 \mathrm{mM}$ of SNP (US Research Nanomaterial Inc., USA) as per previously published literature $[4,8]$. Stock solutions of MeJA in MeOH $50 \%$ and of SNP in water were prepared and sterilized by filtration $(0.2 \mu \mathrm{m}$, Millipore $)$. The filtrates were added to hydroponic media of the plants at different concentrations which have been cited in literature $[4,8]$, and based on the results of these preliminary experiments, concentrations of 50 , and $100 \mu \mathrm{M}$ of MeJA and $0.4,0.8,1.2 \mathrm{mM}$ of SNP were selected for treatments. After treatment, the plants were harvested and washed. The root and aerial parts were separated and aliquots were snap-frozen in liquid nitrogen prior to storage at $-80{ }^{\circ} \mathrm{C}$ until used in biochemical measurements. The remaining parts were shadow-dried before extraction of essential oils.

\section{Characterization of SNP}

A solution of spherical AgNPs was purchased from the US Research Nanomaterial Inc, Houston, TX, USA. According to the manufacturer, the diameter of AgNPs was $30-$ $50 \mathrm{~nm}$ and the purity was $99.99 \%$. According to the manufacturer, the SNPs were $30-50 \mathrm{~nm}$ in diameter and $99.99 \%$ pure. Nonetheless, the nanoparticle size was measured before application by monitoring the change in hydrodynamic diameter using a Zetasizer Nano ZS dynamic light scattering (DLS) instrument (Malvern $3000 \mathrm{HSA}$, UK). The data were analyzed by Zetasizer software, version 6.12 (Malvern, UK). The SNP diameter in the aerial plant extract was determined using the same method.

\section{Membrane lipid peroxidation assay}

The level of membrane lipid peroxidation was determined by measuring malondialdehyde (MDA) as a final product of lipid peroxidation. Aliquots of $0.2 \mathrm{~g}$ frozen samples were homogenized in $10 \%$ trichloroacetic acid (TCA). The homogenate was centrifuged at 10,000 $\times \mathrm{g}$ for $15 \mathrm{~min}$ and $1 \mathrm{~mL}$ of $0.5 \%$ thiobarbituric acid (TBA) was added to $1 \mathrm{~mL}$ of the supernatant. This mixture was incubated for $30 \mathrm{~min}$ in a 100 ${ }^{\circ} \mathrm{C}$ water bath. The reaction tubes were then transferred to an ice-cold water bath. The absorbance of MDA was read at $532 \mathrm{~nm}$ and 600 $\mathrm{nm}$ by a double beam UV-vis spectrophotometer (Cintra6, GBC, Victoria, Australia). The quantity of MDA-TBA complexes formed was calculated using an extinction coefficient of $155 \mathrm{mM}^{-1} \mathrm{~cm}^{-1}$ [9].

\section{Determination of DPPH radical scavenging activity}

The DPPH stock solution was prepared by dissolving $24 \mathrm{mg}$ DPPH into $100 \mathrm{~mL}$ methanol. 
The working solution was obtained by mixing 10 $\mathrm{mL}$ of the stock solution with $45 \mathrm{~mL}$ methanol. Each $250 \mu \mathrm{L}$ sample extract was allowed to react with $250 \mu \mathrm{L}$ of the DPPH solution for $30 \mathrm{~min}$ in the dark. Then the absorbance was read at 517 $\mathrm{nm}$ by spectrophotometry. The percentage of DPPH scavenging activity was calculated as in Eq 1 [9].

Inhibition $(\%)=\{(\mathrm{Ac}-\mathrm{As}) / \mathrm{Ac}\} 100$

where As is the absorbance of the sample and Ac is the absorbance of control.

\section{Total anthocyanin measurement}

To measure anthocyanin content, $0.2 \mathrm{~g}$ of frozen tissue was homogenized completely with acidic methanol (MeOH: $\mathrm{HCl}, 99: 1(\mathrm{v} / \mathrm{v})$ ) and then centrifuged at $12,000 \times \mathrm{g}$ for $15 \mathrm{~min}$. The supernatant was kept in the dark overnight, and then anthocyanin content was determined spectrophotometrically at $550 \mathrm{~nm}$ using an extinction coefficient of $33,000 \mathrm{~cm}^{-1} \mathrm{M}^{-1}$ [9].

\section{Determination of total flavonoids}

Deionized water (1.25 mL) was added to $0.25 \mathrm{~mL}$ of the sample extract, followed by addition of 75 $\mu \mathrm{L}$ of $5 \%$ sodium nitrite $\left(\mathrm{NaNO}_{2}\right)$. After a 6 min incubation, $150 \mu \mathrm{L} 10 \% \mathrm{AlCl}_{3}$ was added, and then the mixture was allowed to stand for another $5 \mathrm{~min}$ before $500 \mu \mathrm{L}$ of $1 \mathrm{M} \mathrm{NaOH}$ was added. The final volume was adjusted to $2.5 \mathrm{~mL}$ with deionized water and the absorbance was measured at $510 \mathrm{~nm}$ [10]. Catechin was used as standard.

\section{Total chlorophyll and carotenoid measurement}

The procedure used to quantitate chlorophyll concentration was based on the absorption of light by aqueous acetone (80 \%) extracts of chlorophyll. The absorbance was read at 645 , 663 , and $663 \mathrm{~nm}$. The contents of chlorophyll a (Chla), chlorophyll b (Chlb), and carotenoids were calculated as in Eqs 2 - 5 [11].

Chla $(\mathrm{mg} / \mathrm{g} \mathrm{FW})=\left[\left\{2.7\left(\mathrm{~A}_{663}\right)-2.69\left(\mathrm{~A}_{645}\right)\right\} \times\right.$ $\mathrm{V} /(\mathrm{W} \times 1000)$

Chlb $(\mathrm{mg} / \mathrm{g} \mathrm{FW})=\left\{22.9\left(\mathrm{~A}_{645}\right)-4.69\left(\mathrm{~A}_{663}\right)\right\} \times$ $\mathrm{V} /(\mathrm{W} \times 1000)$

Chla + Chlb (mg/g FW) $=\left\{20.2\left(\mathrm{~A}_{645}\right)+8.02\right.$ $\left.\left(\mathrm{A}_{663}\right)\right\} \times \mathrm{V} /(\mathrm{W} \times 1000)$
Carotenoids $(\mathrm{mg} / \mathrm{g} \mathrm{FW})=\left\{1000\left(\mathrm{~A}_{480}\right)-1.82\right.$

Chla - 85.02 Chlb\}/198 × V/(W×1000) ...(5)

\section{Extraction and measurement of total saponin content}

Samples were broken into small pieces before being boiled three times to extract saponins. After filtration, the aqueous extract was concentrated and partitioned once with an equal volume of ethyl acetate. The ethyl acetate layer was further partitioned with an equal volume of $n$ butanol, which was subsequently evaporated to dryness. The dry crude powder was used as crude saponin extract. Total saponin content was determined by the vanillin-sulfuric acid method [12]. This extract was mixed with vanillin (8\%, $\mathrm{w} / \mathrm{v})$ and sulfuric acid (72 \%, w/v), and then the mixture was incubated at $60{ }^{\circ} \mathrm{C}$ for $10 \mathrm{~min}$ followed by cooling in an ice water bath for 15 min. Absorbance was measured at $538 \mathrm{~nm}$, and total saponin content was expressed as an oleanolic acid equivalent ( $\mu \mathrm{g} / \mathrm{mg}$ extract).

\section{Cytotoxicity study}

The HeLa cervical cancer cell line was obtained from the Pasteur Institute of Iran. The cells were cultured in RPMI 1640 medium (Gibco, Life Technologies, Carlsbad, CA, USA) supplemented with $10 \%$ fetal bovine serum, 100 units $/ \mathrm{mL}$ penicillin, and $100 \mu \mathrm{g} / \mathrm{mL}$ streptomycin. They were incubated at $37{ }^{\circ} \mathrm{C}$ under $\mathrm{CO}_{2}(5 \%)$ and the medium was renewed every 4 days. Cellular morphology was visualized before and after treatment using an inverted microscope (Nikone TE- 2000, Japan).

The cytotoxic effect of $C$. officinalis $L$ cellular extract was determined by MTT colorimetric assay [9]. Briefly, $100 \mu \mathrm{L}$ of MTT solution (5 $\mathrm{mg} / \mathrm{mL}$ PBS) was added to the cell cultures, which were then incubated at $37{ }^{\circ} \mathrm{C}$ under $5 \%$ $\mathrm{CO}_{2}$ for $4 \mathrm{~h}$ to allow for formazan crystal formation. Then the upper solutions were removed and $250 \mu \mathrm{L}$ of dimethyl sulfoxide was added to each sample to dissolve the formazan crystals. After $30 \mathrm{~min}$, equivalent volumes of the upper solutions were transferred to a 96-well ELISA plate reader (Anthuos 2020, Australia) and the absorbance was measured at $492 \mathrm{~nm}$. Cell viability was determined by assessing the density of live cells as in Eq 6.

Viability of HeLa cells $(\%)=(\mathrm{Sa} / \mathrm{Ca}) 100 \ldots . .(6)$

where $\mathrm{Sa}$ is the absorbance of the sample and $\mathrm{Ca}$ is the absorbance of control. 


\section{Statistical analysis}

All experiments were conducted in triplicate at least three independent times. All data are expressed as the mean values \pm standard deviation (SD). Differences between treatment outcomes were calculated using Student's t-test. Differences were considered statistically significant at $p \leq 0.05$.

\section{RESULTS}

\section{SNP uptake by $C$. officinalis $L$}

The results revealed the presence of SNPs in extract derived from the aerial parts, thus confirming that the particles were taken up from the root, which is the site of absorption (data not shown). The SNP size in the plant extract was approximately $200 \mathrm{~nm}$ which, in comparison to their original size $(40 \mathrm{~nm})$, suggests that the SNPs aggregated within the plant matrix.

\section{Effect of SNPs and MeJA on secondary metabolite production}

The result of the effects of SNPs and MeJA on secondary metabolite content in the marigold is shown in Table 1. Membrane lipid peroxidation (MDA) by the plants increased up to $138 \%$ by SNPs and MeJA treatment. Moreover, treatment of $C$. officinalis $L$ with SNPs and MeJA reduced its DPPH radical scavenging capacity (Table 1 ). Likewise, significant decreases in anthocyanin and flavonoid content were observed in plants treated with MeJA and SNPs.

Treatment of $C$. officinalis $L$ with different concentrations of SNPs and $50 \mathrm{mM}$ MeJA also affected chlorophyll production. We found significant decreases in chlorophylls a and b, as well as total chlorophyll in these plants compared to control plants. In contrast, treatment with 100 $\mu \mathrm{M}$ MeJA significantly increased the chlorophyll content.

Carotenoid content was also affected by the presence of SNPs and MeJA. All concentrations of SNPs investigated resulted in decreased carotenoid content in C. officinalis L. However, although $100 \mu \mathrm{M}$ MeJA increased carotenoid production, treatment of the marigold with $50 \mu \mathrm{M}$ MeJA produced no significant effect on carotenoid content.

The saponin content of plants treated with SNPs and MeJA was significantly higher than those of the control group. The greatest increase in saponin content ( $177 \%$ of the control) was observed in plants treated with $0.4 \mathrm{mM}$ SNPs and $100 \mu \mathrm{M}$ MeJA (Figure 1).

Table 1: Effect of MeJA and SNPs treatments on C. officinalis $L$

\begin{tabular}{|c|c|c|c|c|c|c|}
\hline \multirow[t]{2}{*}{ Parameter } & \multirow{2}{*}{$\begin{array}{c}\text { Control } \\
0\end{array}$} & \multicolumn{3}{|c|}{ SNPs (mM) } & \multicolumn{2}{|c|}{$\operatorname{MeJA}(\mathrm{mM})$} \\
\hline & & 0.4 & 0.8 & 1.2 & 50 & 100 \\
\hline $\begin{array}{l}\text { MDA } \\
\left(\mathrm{mg} \cdot \mathrm{g} \mathrm{FW}^{-1}\right)\end{array}$ & $4.45 \pm 0.3$ & $5.26 \pm 0.6^{*}$ & $4.61 \pm 0.4$ & $6.14 \pm 0.5^{*}$ & $4.58 \pm 0.3$ & $5.01 \pm 0.8^{*}$ \\
\hline $\begin{array}{l}\text { Scavenging } \\
\text { Activity (DPPH \%) }\end{array}$ & $81.53 \pm 8.1$ & $50.42 \pm 2.2^{*}$ & $51.36 \pm 5.2^{*}$ & $64.11 \pm 6.2^{*}$ & $56.20 \pm 8.1^{*}$ & $43.27 \pm 4.7^{*}$ \\
\hline $\begin{array}{l}\text { Anthocyanin } \\
\left(\mathrm{mg} \mathrm{g} \mathrm{FW}^{-1}\right)\end{array}$ & $22.75 \pm 2.8$ & $18.45 \pm 1.5^{*}$ & $11.87 \pm 0.7^{*}$ & $8.38 \pm 1.8^{*}$ & $21.74 \pm 3.0$ & $16.81 \pm 3.0^{*}$ \\
\hline $\begin{array}{l}\text { Flavonoid } \\
\left(\mathrm{mg} \mathrm{g} \mathrm{FW}^{-1}\right)\end{array}$ & $9.07 \pm 0.8$ & $10.40 \pm 0.2$ & $6.62 \pm 0.7^{*}$ & $6.82 \pm 0.0^{*}$ & $5.40 \pm 0.7$ & $2.48 \pm 0.5^{\star}$ \\
\hline $\begin{array}{l}\text { Chlorophyll } \\
\left(\mathrm{mg} . \mathrm{g} \mathrm{FW}^{-1}\right)\end{array}$ & $0.51 \pm 0.02$ & $0.46 \pm 0.02^{*}$ & $0.27 \pm 0.03^{*}$ & $0.13 \pm 0.01^{*}$ & $0.46 \pm 0.01^{*}$ & $0.57 \pm 0.02^{*}$ \\
\hline $\begin{array}{l}\text { Chlorophyll b } \\
\left(\mathrm{mg} \cdot \mathrm{g} \mathrm{FW}^{-1}\right)\end{array}$ & $0.13 \pm 0.02$ & $0.12 \pm 0.02$ & $0.04 \pm 0.01^{*}$ & $0.07 \pm 0.03^{*}$ & $0.14 \pm 0.01$ & $0.22 \pm 0.01^{*}$ \\
\hline $\begin{array}{l}\text { Total Chlorophyll } \\
\left(\mathrm{mg} \cdot \mathrm{g} \mathrm{FW}^{-1}\right)\end{array}$ & $0.64 \pm 0.02$ & $0.58 \pm 0.01$ & $0.31 \pm 0.01^{*}$ & $0.20 \pm 0.01^{*}$ & $0.60 \pm 0.02$ & $0.79 \pm 0.02^{*}$ \\
\hline $\begin{array}{l}\text { Carotenoids } \\
\left(\mathrm{mg} . \mathrm{g} \mathrm{FW}^{-1}\right)\end{array}$ & $5.82 \pm 0.02$ & $4.14 \pm 0.03^{*}$ & $3.91 \pm 0.03^{*}$ & $3.06 \pm 0.02^{*}$ & $6.63 \pm 0.1^{*}$ & $10.23 \pm 0.2$ \\
\hline
\end{tabular}

Asterisks show significant differences with control at $p \leq 0.05$, according to the Student's $t$-test; data are presented as mean $\pm S D(n=3) ; F W=$ fresh weight 


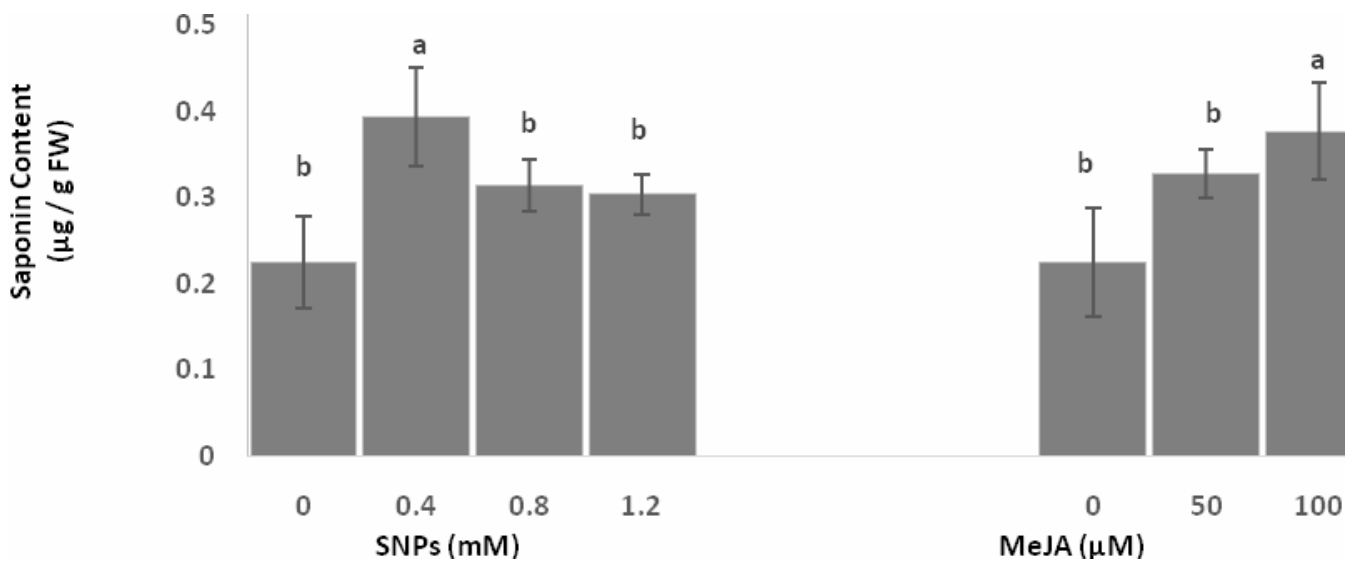

Figure 1: Total saponin content of $C$. officinalis $L$. treated with different concentrations of MeJA and SNPs. Data are presented as the mean $\pm S D(n=3)$; letters different from that of the control indicate that the values are significantly different $(p \leq 0.05)$

\section{Reduced HeLa cell viability following treatment with extract containing SNPs or MeJA}

The effect of SNPs or MeJA on cytotoxicity of the extract is shown in Fig 2. The extract from the control (untreated plants) reduced HeLa cell viability to $80 \%$ (Figure 2). When the plants were treated with MeJA and SNPs, the inhibitory effect of the marigold extract increased. The viability of HeLa cells after exposure to 50 and $100 \mu \mathrm{M}$ MeJA-treated plant extracts was reduced to 60 and $50 \%$, respectively, of the negative control cells. HeLa cell viability after exposure to 0.4 , 0.8 , and $1.2 \mathrm{mM}$ SNP-treated plant extracts decreased to 35,32 and $13 \%$ of control, respectively (Figure 2). These results demonstrate that marigold extract inhibits tumor cell proliferation, especially in the presence of SNPs and MeJA.

\section{DISCUSSION}

In increase in the size of the SNPs suggests that the particles aggregate within plant matrices. Nanoparticles weakly bound together can potentially de-agglomerate and produce smaller sized particles with a larger surface area, which can also be excreted more easily from the body. The extent of particle aggregation can also influence their translocation to other organs [13]. Following the absorption and translocation of SNPs and MeJA within the plants, an increase in membrane lipid peroxidation was observed. This phenomenon has been associated with damage provoked by a variety of environmental stresses and is the most widely measured indicator of oxidative damage due to stress [9]. Polyunsaturated fatty acids are the main membrane lipid components susceptible to peroxidation and degradation by reactive oxygen species (ROS). Studies have shown that treatment of marigold plants with jasmonic acid and its derivatives also induces oxidative stress, membrane damage, and increased MDA concentration within plant cells [14]. The elicitor function of SNPS through increased ROS formation and membrane lipid peroxidation has also been reported in certain fresh water microalgae [15].

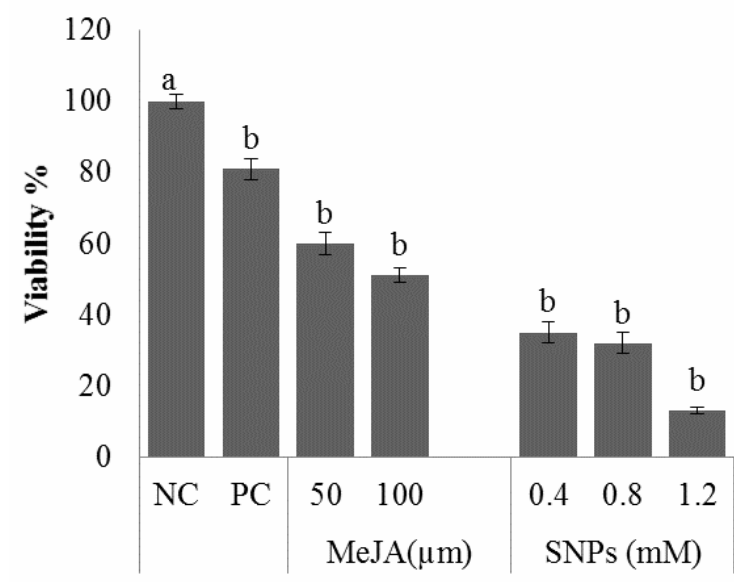

Figure 2: HeLa cell viability after exposure to extract of marigold plant treated with or without MeJA and SNPs. NC; negative control (untreated HeLa cells), PC; positive control (HeLa cells exposed to the extracts of untreated plants). Data are represented as the mean $\pm S D$ of $n=3$ experiments. ${ }^{a b} p \leq 0.05$ (Student's t-test)

Previous studies have also shown that $C$. officinalis $\mathrm{L}$ extract can effectively scavenge DPPH stable free radicals, superoxide, and hydroxyl radicals, as well as inhibit tissue lipid peroxidation in vitro, in a concentrationdependent manner [1,3]. However, our data demonstrates that this capacity decreased after 
treatment with different concentrations of SNP and MeJA, which was consistent with other reports [14]. C. officinalis extract may exhibit reduced radical scavenging capacity after SNP and MeJA treatment due to the reduction in antioxidant phenolic pigments such as anthocyanins and flavonoids. These compounds play a multitude of biological roles, including protection against sun exposure and ultraviolet radiation, free radical scavenging, defense against pathogens, and attraction of predators for seed dispersal [16]. Several reports have also demonstrated changes in flavonoid and anthocyanin content in plants after exposure to exogenous MeJA [10,14].

Chlorophyll derivatives are also involved in a plethora of biological activities. They are known to have antioxidant and antimicrobial activity. Moreover, this molecule stimulates hematopoiesis and the immune response, as well as facilitates the healing of ulcers, wounds, and burns [17]. Chlorophylls also have antimutagenic, anti-carcinogenic, and antiinflammatory properties and can protect DNA from damage by carcinogens and other toxins [18]. Ueda and Saniewski reported that MeJA can stimulate chlorophyll formation when present in the basal part of tulip bulbs [19]. However, Oukarroum [15] reported a reduction in total chlorophyll in two green algae, Chlorella vulgaris and Dunaliella tertiolecta, following exposure to $0.01,0.1,1$ and $10 \mathrm{mg} / \mathrm{L}$ SNPs, which is consistent with our data.

Carotenoids are isopernoid compounds that differ from anthocyanins and betalains in that they participate in photoprotective functions during photosynthesis. Carotenoids play an important role in human nutrition and health by providing pro-vitamin A and eliciting anti-cancer activities. Several studies have reported that the anti-cancer effect of carotenoids is independent of pro-vitamin A activity [20]. Finally, these compounds are very effective quenchers of singlet oxygen and free radicals, which are important in cancer etiology [20].

Saponins are another group of secondary metabolites of marigold. They are natural glycosides that exhibit cytotoxic, antimicrobial, cholesterol-lowering, and anticancer properties. Fungi static and fungicide activities of saponins are also reported [21]. Marigold synthesizes a significant quantity of oleanane saponins, which are found in all organs of this plant including the flowers. Several biological properties have been reported for the oleanolic acid glycosides present in $C$. officinalis $\mathrm{L}$, including antifungal activity against Trichoderma viride. The antibiotic activity of oleanolic acid and its derivatives against Escherichia coli was recently reported. Moreover, the wormicidal activity of oleanolic acid glycosides against the parasitic nematode Heligmosomoides polygyrus was published [3].

Coincident with other reports [21], C. officinalis L extract showed a potent inhibition of tumor cell proliferation in vitro that increased with the presence of SNP and MeJA. The anticancer, antibacterial, fungicidal, and antioxidant activities of $C$. officinalis $L$ have been frequently attributed to saponins and carotenoids produced by the plant $[3,20,22]$. Our results suggest that treatment of the marigold plant with SNPs and MeJA can be a good strategy for increasing its medicinal properties.

\section{CONCLUSION}

Based on the results presented here, it is obvious that treatment of Calendula officinalis $\mathrm{L}$ extract with SNPs and MeJA elicits an increase in ROS formation and peroxidation of membrane lipids. The increase in carotenoids and saponins also improves the cytotoxic and anticancer activity of this plant extract, making it a potentially effective therapeutic material for treating disease and cancer.

\section{ACKNOWLEDGEMENT}

This work was supported by grant no. 90000972 from the Iran National Science Foundation (INSF) to FGH on "The effects of MeJA and SNPs on medicinal compounds of plants".

\section{REFERENCES}

1. Muley B, Khadabadi S, Banarase N. Phytochemical constituents and pharmacological activities of Calendula officinalis Linn (Asteraceae): A Review. Trop J Pharm Res. 2009; 8: 455-465.

2. Kalvatchev Z, Walder R, Garzaro D. Anti-HIV activity of extracts from Calendula officinalis flowers. Biomed Pharmacother. 1997; 51: 176-180.

3. Szakiel A, Ruszkowski D, Janiszowska W. Saponins in Calendula officinalis L. - structure, biosynthesis, transport and biological activity. Phytochem Rev. 2005; 4: 151-158.

4. Belhadj A, Telef N, Saigne C, Cluzet S, Barrieu F, Hamdi $S$, Merillon J. Effect of methyl jasmonate in combination with carbohydrates on gene expression of PR proteins, stilbene and anthocyanin accumulation in grapevine cell cultures. Plant Physiol Biochem 2008; 46: 493-499. 
5. Creelman R, Mullet JE. Biosynthesis and action of jasmonates in plants. Ann Rev Plant Mol Biol. 1997; 48: 355-381.

6. Belhadj A, Telef N, Saigne C, Cluzet S, Barrieu F, Hamdi $S$, Merillon J. Effect of methyl jasmonate in combination with carbohydrates on gene expression of $P R$ proteins, stilbene and anthocyanin accumulation in grapevine cell cultures. Plant Physiol Biochem. 2008; 46: 493-499.

7. Savithramma N, Rao ML, Rukmini K,devi PS, Antimicrobial activity of silver nanoparticles synthesized by using medicinal plants. Int J ChemTech Res. 2011; 3: 1394-1402.

8. Seif Sahandi M, Sorooshzadeh A, Rezazadeh S, Naghdibadi $H A$. Effect of nano silver and silver nitrate on seed yield of Borage. J Med Plant Res. 2011; 5(2): 171-175.

9. Bemani E, Ghanati F, Yousefzadeh Boroujeni L, Khatami F. Antioxidant activity, total phenolics and taxol contents response of hazel (Corylus avellana L.) cells to benzoic acid and cinnamic acid. Not Bot Horti Agrobo. 2012; 40(1): 69-73.

10. Wang SY, Bowman L, Ding M. Methyl jasmonate enhances antioxidant activity and flavonoid content in blackberries (Rubus sp.) and promotes antiproliferation of human cancer cells. Food Chem. 2008; 107(3): 1261-1269.

11. Arnon D. Copper enzymes in isolated chloroplasts polyphenoloxidase in Beta vulgaris plant physiol. 1949; 24: 1-15.

12. Hiai S, Qura H, Nakajima T. Color reaction of some sapogenins and saponins with vanillin and sulfuric acid. Planta Med. 1976; 29: 12116-12219.

13. Stebounova L, Guio E, Grassian V. Silver nanoparticles in simulated biological media: a study of aggregation, sedimentation, and dissolution. Journal of Nanopart Res. 2011; 13: 233-244.
14. Maksymiec $W$, Krupa $Z$. The in vivo and in vitro influence of Methyl Jasmonate on oxidative processes in Arabidopsis thaliana leaves. Acta Physiol Plant. 2002; 24: 351-357.

15. Oukarroum A, Bras S, Perreault F, Popovic R. Inhibitory effects of silver nanoparticles in two greenalgae, Chlorella vulgaris and Dunaliella tertiolecta. Ecotox Environ Safe. 2012; 78: 80-85.

16. Matysik G, Wojciak-Kosior M, Paduch R. The influence of Calendula officinalis flos extract on cell cultures and the chromatographic analysis of extracts. Journal of Pharmaceut Biomed. 2005; 38: 285-292.

17. Moiseeva M, Mikhailesc G. Application of chlorophyll derivatives in medicine. In: V.G. Bespalov VG and Nekrasova VB editors. "Study and application of therapeutic-prophylactic medications based on natural biologically active compounds". Eskulap: $S P b$; 2000.p. 80-88.

18. Egner PA, Munoz A, Kensler TW. Chemoprevention with chlorophyll in in individuals exposed to dietary aflatoxin. Mutat Res. 2003; 523-524: 209-216.

19. Ueda J, Saniewski M. Methyl jasmonate induced stimulation of chlorophyll formation in the basal part of tulip bulbs kept under natural night condition. J Fruit Ornam Plant Res. 2006; 14: 199-210.

20. Mayne S. B-carotene, carotenoids and disease prevention in humans. FASEB J. 1996; 10: 690-701.

21. Jimenez-Medina E, Garcia-Lora A, Paco L, Algarra I, Collado A, Garrido F. A new extract of the plant Calendula officinalis produces a dual in vitro effect: cytotoxic anti-tumor activity and lymphocyte activation. BMC Cancer. 2006; 6: 119. doi: 10.1186/1471-2407-6-119.

22. Sindambiwe J, Calomme M, Geerts S, Pieters L, Vlietinck A,Berghe DV. Evaluation of biological activities of triterpenoid saponins from Maesa lanceolata. J Nat Prod. 1998; 61: 585-590. 